\title{
EL PORTUGUÉS ME HACE FELIZ: EMOÇÕES COMPARTILHADAS EM PRÁTICAS HUMANIZADORAS DE ENSINO E APRENDIZAGEM DE PORTUGUÊS LÍNGUA ESTRANGEIRA EM UM CONTEXTO MEDIADO PELO COMPUTADOR ${ }^{1}$
}

\section{Marta Lúcia Cabrera Kfouri KANEOYA*}

- RESUMO: Qual a relação entre aprender uma língua e sentir-se feliz? Que contextos e açóes podem promover uma aprendizagem de línguas mais humanizadora? Tendo por pressuposto o "aprender línguas positivamente" (GOMES DE MATOS, 1996, 2010, 2014), este trabalho tem por objetivo caracterizar um contexto virtual multilíngue e multicultural (DE OLIVEIRA, 2014), que possibilita práticas humanizadoras de ensino/ aprendizagem de português língua estrangeira (PLE). Nesse contexto, uma interagente mexicana manifesta suas emoçóes e sentimentos positivos sobre aprender PLE com uma interagente brasileira. Ela também reflete sobre suas experiências anteriores e menos humanizadoras de aprendizagem dessa língua e sobre o papel do professor na promoção do bem-estar na aprendizagem. Os resultados sugerem que as emoçóes devem ser consideradas no estabelecimento de uma aprendizagem de pertencimento e de identificação em um contexto multilíngue e multicultural (MURPHEY; PROBER; GONZALES, 2010; BARCELOS, 2010; COELHO, 2010; PELLIM, 2010; DE OLIVEIRA, 2014) e que o teor humanizador das interaçóes favorece o sucesso do processo de ensino/aprendizagem e de reflexão do professor de línguas nesse contexto.

- PALAVRAS-CHAVE: Ensino/aprendizagem de português língua estrangeira. Emoçóes. Abordagem humanizadora. Contexto multilíngue e multicultural. Formação do professor de línguas.

\footnotetext{
* UNESP - Universidade Estadual Paulista. Instituto de Biociências, Letras e Ciências Exatas Departamento de Educação. São José do Rio Preto - SP - Brasil. 15054-000 - mlkfouri@ibilce.unesp.br

1 Este trabalho traz uma análise renovada de parte dos dados de minha tese de doutorado, intitulada A formação inicial de professores de linguas paralem contexto mediado pelo computador (teletandem): um diálogo entre crenças, discurso e reflexão profissional, defendida em 2008, junto ao Programa de PósGraduação em Estudos Linguísticos da UNESP, campus de São José do Rio Preto-SP.
} 


\section{Considerações iniciais}

$\mathrm{Na}$ Declaração Universal dos Direitos Linguísticos (UNESCO, 1996), também conhecida como Declaração de Barcelona, aponta-se que o ensino de línguas (Seção II, Artigo 23) deve ter como fundamento a garantia da "[...] diversidade linguística e cultural e das relaçóes harmoniosas entre as diferentes comunidades linguísticas do mundo inteiro, sendo que todos têm direito a aprender qualquer língua." No que concerne à cultura, encontra-se no mesmo documento a ideia de que todas as comunidades linguísticas têm direito a promover sua língua por meio de formas diversas de expressão cultural, bem como ao acesso a todas as "programaçóes interculturais, mediante a difusão da informação e ao apoio às atividades de ensino de línguas a estrangeiros" (Seção V, Artigos 41 e 44).

Tal declaração alinha-se ao anteriormente recomendado na Declaração do Recife, elaborada em 1987, no Seminário Internacional sobre Direitos Humanos e Culturais da Faculdade de Direito do Recife, da Universidade Federal de Pernambuco, e da qual o linguista aplicado Francisco Gomes de Matos foi articulador ${ }^{2}$. Em uma visão filosóficopedagógica humanizadora, o autor declara ser altamente desejável que os direitos dos aprendizes de ouvir e ser ouvidos em contextos de ensino/aprendizagem de línguas, de comunicar-se para o bem e de ser avaliados humanizadoramente sejam respeitados e praticados, fundando um conceito de ensino que denomina "paz comunicativa" (GOMES DE MATOS, 2010). Nesse sentido, favorecer a autoimagem positiva e a autoestima linguística dos alunos é algo fundamental, promovendo-lhes uma confiança mínima como usuários da língua, que lhes garanta, consequentemente, uma autoestima lexical, gramatical, argumentativa e cultural, ensinando-os a "comunicar-se para o bem" e "para o bem da humanidade" (GOMES DE MATOS, 2010, p.31).

Em congruência com essas ideias, teóricos como Murphey, Prober e Gonzales (2010) afirmam que, tal como ocorre com os indivíduos em suas relaçóes sociais, o sentimento de pertencimento emocional precede a aprendizagem, ou melhor, o respeito e a aceitação da diversidade são conceitos importantes para a saúde emocional do aprendiz e para o estabelecimento da sensação de pertencimento e de identificação com um grupo, uma cultura, uma língua. Para os autores, aprender é emocionar-se e manifestar emoçóes positivas pode ser um processo benéfico para o aprendiz, que aumenta a empatia com a língua/cultura e a participação em grupos de uso dessa língua. O processo contrário, ou seja, o da exclusão, poderia afetar o estado emocional do aprendiz, enfraquecer sua capacidade de aprender, sua sensibilidade e sua empatia com a língua/cultura, gerando estímulos psicológicos agressivos e de autodefesa em contextos sociais de aprendizagem de línguas. Usando outras palavras,

\footnotetext{
O Prof. Dr. Francisco Gomes de Matos é professor emérito no Programa de Pós-Graduação em Letras e Linguística da Faculdade Federal de Pernambuco e o principal representante, no Brasil, da Linguística da Paz. Em 1984, fez um apelo a UNESCO pela elaboração da Declaração Universal dos Direitos Linguísticos.
} 
o comportamento alheio e a interpretação que fazemos disso podem influenciar o modo como compreendemos uma cultura, promover estereótipos e relaçóes pouco socializadoras envolvendo línguas.

Nesse sentido, faz-se fundamental o papel do professor ou de qualquer outro indivíduo que promova a aprendizagem de uma língua, no sentido de motivar a colaboração e valorizar aquilo que o aprendiz já possui em termos de conhecimento linguístico, cultural e pessoal, empenhando-se na humanização do ensino e na promoçáo do bem-estar na aprendizagem.

Com base nesses pressupostos, este trabalho tem como cenário de análise e reflexão o contexto teletandem, um ambiente virtual de aprendizagem de línguas criado no Brasil, que envolve pares de falantes proficientes em diferentes línguas (nativas ou não) trabalhando, colaborativamente, para aprender a língua um do outro, tendo por lema “eu ajudo você a aprender minha língua e você me ajuda a aprender a sua!”. Para isso, os interagentes, alunos universitários de diferentes países, recorrem a aplicativos gratuitos como Windows Live Messenger ou Skype para se comunicarem, em tempo real, por meio de voz, texto (leitura e escrita) e imagens de vídeo, veiculadas por uma webcam (TELETANDEM BRASIL, 2015).

Observamos, assim, o potencial multilíngue e multicultural desse contexto (DE OLIVEIRA, 2014), no sentido de envolver duas interagentes com experiências linguístico-culturais acadêmicas diversas. De um lado, Natália, interagente brasileira, licencianda em Letras Português-Espanhol por uma universidade pública do interior paulista e sem experiência profissional docente no ensino de línguas ou de vivência no exterior. Do outro, encontramos Helen, interagente mexicana, falante bilíngue de espanhol e inglês e, anteriormente, estudante de português língua estrangeira (PLE) em Portugal, cursa o Doutorado em Linguística Aplicada na Espanha e já tem experiência de ensino de espanhol e de inglês como línguas estrangeiras em uma universidade pública do México. Nesse ambiente, em que predomina um "esforço compartilhado com o parceiro com vistas à aprendizagem de línguas", e que se caracteriza também como "um espaço para a construção de relacionamentos agradáveis" (TELETANDEM BRASIL, 2015), olharemos o papel das emoçóes no sucesso da aprendizagem de línguas, especialmente do PLE, e a construção de uma concepção humanizadora sobre ensinar e aprender línguas.

\section{Algumas reflexões teóricas}

A visão da complexidade do papel do professor na promoção do bem-estar na aprendizagem de línguas, ou de todo aquele que se engaja na educação de seu "próximo linguístico" (GOMES DE MATOS, 2010, p. 26), defendida neste trabalho, está embasada em princípios de garantia da autoestima profissional, da confiança no ensino e no bem embutido no trabalho docente, por meio de uma formação justa e que garanta ao professor não se sentir inferiorizado, nem em relação às suas competências 
e ações pedagógicas, nem em relação a sua língua/cultura, e, por fim, nem em relação ao valor de sua própria profissão. Essas açóes favorecem, direta e indiretamente, o bemestar na sala de aula de línguas, o respeito e a valorização mútuas (entre professor e alunos e entre alunos) e a capacidade de dialogar para o bem (de si mesmo e do outro). Passamos a agir, pois, de modo a aprender a nos comunicar pacificamente, para o bem da humanidade e do meio-ambiente (FRIEDRICH, 2012).

Nesse sentido, professores de línguas podem compreendem a natureza cognitiva, sociocultural e humanizadora do uso da linguagem, em todo seu potencial para gerar a paz comunicativa (GOMES DE MATOS, 2010). Como tal, devem conscientizarse de seu papel como promotores de competência comunicativa humanizadora em seus alunos, ou seja, não só para comunicar-se bem em uma língua estrangeira, mas também para comunicar-se para o bem. Entre as açóes de professores promotores da paz comunicativa em línguas, Gomes de Matos destaca empenhar-se em humanizar seu discurso, seu vocabulário e sua construção frasal; aprender a observar os efeitos de suas escolhas lexicais e gramaticais em seu "próximo linguístico", ou seja, observar os efeitos da comunicação e do uso de expressóes mais humanizadas e menos agressivas; aprender a monitorar sua produção textual, no sentido de humanizar, principalmente, sua escrita (GOMES DE MATOS, 2010, p.28). Essas açóes, segundo o autor, podem valorizar a percepçáo intercultural e a competência linguocultural e comunicativa de todos os envolvidos.

Para Murphey, Prober e Gonzales (GOMES DE MATOS, 2010), professores e alunos de línguas podem fazer uso de estratégias positivas que promovam interaçóes saudáveis e realmente significativas em contextos de ensino/aprendizagem. Para os autores, atitudes comunicativas simples, como tratar-se pelo nome, conhecer as aspiraçôes dos aprendizes e convidá-los a participar das interaçôes já podem produzir efeitos positivos na aprendizagem de línguas. Além disso, outras atitudes de encorajamento por parte dos professores, tais como incentivar o trabalho em grupos, em que um ajude o outro a aprender e a superar desafios de aprendizagem; reconhecer publicamente a presença positiva de cada aprendiz e de suas contribuiçóes para a sala; destacar o valor de características como amizade e cooperação na aprendizagem de línguas devem ser consideradas e praticadas.

Indo além, o senso de pertencimento dos alunos não deve se limitar à sala de aula e os professores de línguas devem encorajar os aprendizes a refletir sobre seus comportamentos em busca de identificação em um ou mais grupos sociais. Questionarse sobre a ampliação de sua capacidade para fazer amigos a partir da aprendizagem de uma nova língua; de ajudar os outros e de pedir ajuda; envolver-se em atividades parassociais (na internet, pelo celular ou em outras mídias); melhorar o desempenho de um grupo no qual esteja envolvido, por meio de sua própria contribuiçáa; ser capaz de cumprimentar alguém hoje de quem não era próximo antes; ser capaz de praticar atividades fora de casa e da escola; e manter amizades são reflexóes importantes para dimensionar o grau de pertencimento a determinado(s) grupo(s). 
Murphey, Prober e Gonzales (2010) salientam que são características relevantes em ambientes promotores de um senso de pertencimento nos aprendizes a prática do respeito pela diversidade e a compreensão das vantagens de se aprender para a diversidade, bem como a reflexão sobre ideias complexas que envolvem emoção e razão, no sentido de se modificar situaçóes estereotipadas, comportamentos de abandono de responsabilidade e de negligência e de perda da esperança, entre outras, perfeitamente adequadas a contextos multilíngues e multiculturais, como no caso deste trabalho, conforme comprovaremos adiante.

De Oliveira (2014) afirma que, enquanto usuários de uma língua (qualquer que seja ela), as escolhas linguísticas que fazemos são diferentes, coerentes e compreensíveis em seus contextos de uso. Porém, segundo a autora, professores de línguas nem sempre têm a compreensão dessas diferenças, ensinando modelos e padróes linguísticos abstratos e generalizados, fortemente apoiados em razóes pedagógicas, em contextos de aprendizagem de línguas. Propondo uma visão questionadora dessa uniformidade no ensino, com base em Kramsch (2013), a autora acima citada defende que, na atualidade, mesmo em contextos de ensino onde o foco seja um sistema linguístico padrão, a formação e a atuação docentes devem estar centradas no desenvolvimento das competências multilíngue e multicultural. Para isso, as licenciaturas deveriam promover o que denomina "virada multilíngue" na formação docente (DE OLIVEIRA, 2014, p.267), no sentido de se formar professores que sintam potencial para atuar como multilíngues e multiculturalistas, ainda que sua licenciatura seja dupla, como costuma ocorrer na maioria das universidades brasileiras, das quais os professores saem habilitados em português e em uma língua estrangeira, mas acabam se especializando como professores de apenas uma das duas. Na visão de De Oliveira (2014), qualquer contexto de ensino/aprendizagem de línguas tem, por natureza, potencial para ser multilíngue e multicultural, e, nesse sentido, faz-se coerente fundamentar a formação do professor de línguas em uma visão multilíngue, que representa a possibilidade de muitas línguas em contato, dentro e fora dos limites da escola. Na perspectiva multilíngue, mesmo em contextos bilíngues, como é o caso do teletandem, pode haver mais que duas línguas ou variantes representadas, proporcionando a noção de "multidão" linguístico-cultural (DE OLIVEIRA, 2014).

Nesse caminho, professores multilinguisticamente engajados devem ser capazes de: 1) compreender a relaçáo entre língua, cultura e identidade e desenvolver uma consciência sobre a dimensão sociopolítica de uso de língua e de educação linguística; 2) mostrar respeito e interesse pelas diferentes línguas de origem dos aprendizes, desenvolvendo atitudes positivas e de incentivo ao seu engajamento na aprendizagem; 3) advogar a favor dos direitos dos aprendizes, no sentido de trabalhar para melhorar um ou mais aspectos de suas experiências educacionais e de promover uma aprendizagem de língua estrangeira bem-sucedida, respeitando-se os diferentes contextos locais e nacionais, bem como os fatores sociais e políticos que os sustentam; 4) compreender a diversidade de resultados, experiências e proficiências 
dos aprendizes, de modo a ser capaz de ajustar seu ensino e o currículo às necessidades e recursos do contexto e seus envolvidos; 5) em termos de aquisição de segunda língua, reconhecer: a importância de um input compreensível e de acordo com o nível de competência dos aprendizes; oportunidades de interação social para uma comunicação autêntica na língua; que habilidades e competências na língua materna podem ser transferidas na aprendizagem/aquisição de outra língua; que a ansiedade quanto ao seu desempenho em uma língua estrangeira/segunda língua pode interferir na aprendizagem (DE OLIVEIRA, 2014).

No livro Emoçôes, Reflexóes e (Trans)form(açôes) de Alunos, Professores e Formadores de Professores de Linguas, organizado pela profas. Ana Maria Ferreira Barcelos e Hilda Simone Henriques Coelho, encontramos uma reuniáo de trabalhos de autores que apresentam e refletem sobre a formação do professor de línguas em um projeto de educação continuada para professores de língua inglesa, sob a coordenação das organizadoras. Da obra, destacamos aqui três capítulos, os de Barcelos (2010), Pellim (2010) e Coelho (2010). Ao refletir sobre as relaçóes sociais de confiança mútua que devem se instaurar entre participantes de processos educativos, Barcelos (2010) sugere a necessidade de se cultivar o cuidado com o outro. Ouvir as histórias dos participantes e considerar as emoçóes como partes do "processo de ensinar, aprender, aprender a ensinar e de aprender a formar professores" (BARCELOS, 2010, p.62) são açôes coerentes com essa perspectiva. Segundo a autora, emoçôes são propulsoras de mudanças e estáo intimamente relacionadas ao ensino, que deve ser construído como um espaço de acolhimento e de pertencimento emocional. Para Pellim (2010), é necessário que o professor "se dispa" de um modelo racional de ensino/aprendizagem e passe a considerar "emoçóes, sentimentos, desejos, crenças e preconceitos" que perpassam os processos de ensinar e aprender, sobretudo línguas, favorecendo um entrelaçamento entre as vidas profissional e pessoal e a construção das identidades de professores e de aprendizes. Para o autor, é sensato reconhecer, ainda, que esses participantes assumam outras identidades, como as de mães, pais, esposas, maridos, seguidores(as) de determinada religião e outras, que, muitas vezes, não permitem essa separação entre os lados emocional e racional. Coelho (2010), por sua vez, reflete sobre a questão do despertar das emoçóes e do "amor", observando que as pessoas vivenciam experiências e observar a realidade de maneiras distintas, ainda que estejam inseridas em um mesmo ambiente. A autora considera que, ao manifestarmos nossas dificuldades (pensemos na situação de aprendizagem de uma nova língua, conforme o foco deste trabalho) e questionar o outro sobre elas, pode despertar nesse outro o interesse por nossas dúvidas, o desejo de conversar sobre elas, de nos acolher e proporcionar um bem-estar, que a autora afirma ter sua base na "emoção do amar" (COELHO, 2010, p.89). Coelho também afirma, assim como Pellim (2010), que não podemos separar emoção de razão, pois é justamente esse entrelaçamento que nos leva a agir de forma humanizadora. E, assim, coordenando nossas açôes, definimos o meio e os sistemas em que existimos. 
Veremos, a seguir, como o meio de aprendizagem de línguas analisado (virtual), bem como o sistema em que ele se configura (teletandem), promovem a construção de discursos para o bem. Nesse ambiente, veremos como a interagente mexicana, que aprende PLE, manifesta suas razóes e emoções vivenciadas e formuladas tanto nessa experiência quanto em experiências anteriores, e como os princípios de uma abordagem humanizadora estão presentes nas ações da interagente brasileira, a qual, por sua vez, reflete sobre sua própria formação inicial como professora de PLE.

\section{Metodologia e caracterização das participantes}

Como já sabemos, o contexto analisado é o ambiente virtual teletandem, onde ocorrem interaçôes entre uma brasileira e uma mexicana, no sentido de uma aprender a língua de proficiência da outra. Um ponto interessante a ressaltar é que, no teletandem, nenhum dos interagentes é tomado como professor e nem há uma agenda prévia de conteúdos a serem abordados na aprendizagem das línguas. Cada interagente é visto como tutor de sua língua materna e aprendiz de outra língua, e cada parceria assume uma caracterização própria, dependendo daquilo que os interagentes mostram estar dispostos e interessados em aprender.

A interagente Helen é mexicana, doutoranda em Linguística Aplicada na Espanha. Helen é filha de mãe mexicana e pai estadunidense, caracterizando-se como falante bilíngue de espanhol e inglês. A participante enfatiza que teve uma forte formação linguística inspirada no inglês desde sua infância até o ensino secundário, já que os avós paternos americanos sempre a presenteavam com livros de contos e discos na língua. Helen também afirma que, embora seus pais sempre conversassem com ela usando as duas línguas, aprendia espontaneamente algumas palavras primeiramente em inglês e depois em espanhol. Quando estava em idade de escolarização, foi matriculada em uma escola bilíngue, na qual considerava as aulas de inglês "fáceis e divertidas", enquanto as de espanhol eram "difíceis e sérias", conforme podemos ler em sua autobiografia. Estando prestes a concluir o ensino médio, seus pais passaram por uma crise financeira que a levou a estudar em uma escola pública, na qual, segundo ela, sabia mais inglês do que seus professores. A necessidade financeira também a levou a ministrar aulas de espanhol como língua estrangeira e de inglês para crianças, experiências que se caracterizaram como suas primeiras no ensino de línguas. A partir desse período, seu contato com a língua inglesa na escola tornouse mais escasso e o espanhol se sobressaiu, fato pelo qual considera o idioma como sua língua de proficiência, já que hoje escreve, fala e se relaciona socialmente muito mais em espanhol. Durante a licenciatura, começou um curso de francês, mas, àquela época, teve poucas oportunidades de usar a língua. Os estudos em inglês só foram retomados após a licenciatura, em um curso de formação continuada para professores de língua inglesa, considerado por Helen mais importante de sua formação profissional. Posteriormente, durante os estudos de doutorado na Espanha, 
ensinou francês a uma amiga portuguesa, que, em troca, ensinava-lhe português, de maneira muito informal, realizando-se, assim, sua primeira experiência em tandem presencial. A partir desse contato com a língua portuguesa e após uma viagem a Portugal, decidiu estudar português, língua que a faz feliz, segundo considera. Por essa razáo maior, interessou-se pelo teletandem, vislumbrando a possibilidade de comunicação real com Natalia, licencianda em Letras e falante nativa de português do Brasil, cuja música e literatura lhe "soam poesia". Helen também estuda português europeu em contexto presencial de sala de aula, enquanto conclui seus estudos de doutorado na Espanha.

Embora seja óbvio que Helen já possua considerável experiência em ensino de línguas e esteja em processo avançado de formação profissional, e, ainda, que Natalia, apesar de graduanda em Letras, já desenvolva uma experiência docente como aluna-estagiária no ensino de línguas há dois anos, é importante explicitar que ambas vivenciam, pela primeira vez, a experiência de ensinar e aprender línguas em uma modalidade de ensino mediada pelo computador. Ainda que tenhamos consciência da diversidade de formação e de experiências docentes entre ambas, sabemos, em contrapartida, que tal fato pode representar possibilidades de resultados igualmente enriquecedores para ambas, sobretudo no que diz respeito à manifestação de emoções e ao trato humanizador dado às ações de ensinar e aprender a língua uma da outra.

Dessa maneira, este trabalho constituiu-se como uma pesquisa interpretativista de cunho etnográfico e caráter colaborativo (ANDRÉ, 2000), cujos instrumentos de coleta de dados considerados neste artigo foram as gravaçôes das interações e das mediaçóes em áudio e a autobiografia de $\mathrm{Helen}^{3}$. O procedimento de análise adotado foi o de categorizaçáo dos dados, o qual, de acordo com Burns (1999), permite ao pesquisador ter uma visão mais clara de seu corpus, triangular dados e analisá-los de forma mais confiável.

\footnotetext{
3 Mediações eram encontros virtuais semanais entre Natália, a interagente brasileira, e eu, que, além de pesquisadora, exercia o papel de mediadora na pesquisa, isto é, ouvia, sugeria e comentava sobre as práticas, dúvidas e crenças que ela me apresentava ao ensinar PLE a Helen. A mediação não tinha um caráter prescritivo, apenas funcionava como meio para que a própria interagente refletisse, sobre suas açôes em teletandem e, a partir daí, continuasse seu trabalho. Vimos a mediação como um ambiente humanizador, à medida que a interagente pode manifestar suas dificuldades, ser ouvida e aconselhada, caso manifeste esse desejo. Os demais instrumentos de coleta de dados utilizados na pesquisa em sua íntegra náo são relevantes para este recorte de análise (KFOURI-KANEOYA, 2008).
} 


\section{Resultados a partir da análise}

\section{A manifestação de emoções e o teor humanizador do discurso da interagente mexicana na aprendizagem de PLE: o que revelam os dados analisados}

Trazemos agora uma breve descrição e a ilustração de algumas das categorias de análise dos dados enfocados neste trabalho.

A primeira delas refere-se aos fatores motivacionais considerados por Helen - de ordem econômica, linguística, cultural e afetiva - em sua escolha pelo estudo do PLE a ser estudado ao terminar as disciplinas do doutorado na Espanha. Destacamos, em negrito, as que se referem às emoçóes positivas manifestadas por ela ao se referir à língua portuguesa, bem como à literatura e à música brasileiras:

En España, al terminar las materias del doctorado, decidi que quería aprender otra lengua [...] Elegi el portugués por varios motivos : el curso es más barato que el de otras lenguas (pero también lo son el italiano, ruso o japonés); en las pocas clases que tomé con mi amiga me pareció que la lengua se me facilitaba; al momento de decir la lengua ya habia viajado a Portugal y me encantó, lo cual me predispone favorablemente para aprender y practicar la lengua; y, finalmente, quería estudiar una lengua que me gustara, que no supusiera para mi un esfuerzo demasiado grande (como el alemán) ya que mi prioridad aqui es mi investigación de doctorado, pero sobretodo quería estudiar algo que me hiciera feliz y el portugués me hace feliz. La literatura me parece muy reflexiva, la música brasileña me parece muy alegre y ambas variedades tienen una sonoridad bellísima: cuando uno babla parece que está cantando, todo suena a poesía. (Autobiografía de Helen).

Parece-nos claro que, após um período em que cursou disciplinas do doutorado (e que imaginamos ter sido exaustivo), Helen busca estudar uma nova língua movida por fatores estimulantes e que lhe traga bem-estar: uma língua fácil, encantadora, cuja sonoridade seja bela como poesia e de literatura reflexiva. E encontrou tudo isso no português, "a língua que a faz feliz". Portanto, antes mesmo de iniciar sua participação nas interaçóes em teletandem, Helen já tinha como propósito aprender uma língua que lhe fizesse bem.

Em outro trecho de sua autobiografia e, ainda, em duas pequenas passagens de interaçôes, Helen também revela, em outra categoria, seu contentamento pelo fato de a aprendizagem de PLE em teletandem proporcionar-lhe um contato comunicativo mais prazeroso e atrativo, além de retornos personalizados sobre a língua, gerando uma diminuição de bloqueios no uso da língua. Vejamos: 
Las interaciones con Natália me ayudan mucho: escucho una voz y un acento distinto al de clase, aprendo cosas sobre la gramática de la lengua con una corrección y retroalimentación personalizada, también aprendo sobre cultura y costumbres. [...] Lo más importante es que me motiva. La comunicación con Natália es real: uso la lengua para expresar mis pensamientos y sentimientos y no hay nada que motive tanto como ese sentimiento de logramos entendernos. (Autobiografia de Helen).

Natália: Helen, se você quiser pode terminar a correção de sua tese.

Helen: Muito obrigada, eu vou voltar a meu trabalho aunque eu gosto muito de chatear com você.

Natália: Eu também, é um momento de relaxamento.

Helen: Sim, eu penso em otras coisas, eu me relajo. (Interação 2, por chat).

Natália: Não precisa ficar nervosa, nossas línguas são próximas.

Helen: E verdade mais eu creio que o português é muito mais musical. Eu gosto desso. [...] É, não sei, bonito usar a língua fora da classe! (Interação 1, por chat).

Nos trechos acima, cujas passagens de relevância aparecem destacadas, observamos que as estratégias de Natália para que Helen aprenda PLE são fundamentalmente humanizadoras, no sentido de deixar sua interagente mexicana motivada a expressar pensamentos e sentimentos, em busca do sentimento de compreensão mútua. Helen caracteriza a comunicação com Natália como real, o que sugere a saúde emocional da interação de ambas e sua predisposição em estabelecer uma paz comunicativa. Helen dá ênfase também a aspectos fonéticos da aprendizagem de PLE com Natália, cuja voz e entonação são diferentes das praticadas pela professora presencial, uma portuguesa. Em relação a outros aspectos e vantagens da aprendizagem em teletandem, gosta de ter um retorno personalizado de tópicos gramaticais e de aprender sobre cultura e costumes brasileiros. Por outro lado, é também um momento de descontração, no qual pode pensar em coisas diferentes das de seu cotidiano e relaxar. Portanto, podemos notar que esse ambiente virtual amplia o conceito tradicional de aprendizagem de línguas, que passa a ser vista como uma aprendizagem aberta para a vida (BRAMMERTS, 2002).

Em uma de suas últimas interaçóes, Natália e Helen conversam sobre as diferenças notadas pela mexicana entre a aprendizagem de PLE presencial, com a professora Catarina, portuguesa, e a virtual, no teletandem, o que constituiu mais uma categoria. Novamente, Helen associa os resultados alcançados a um sentimento de bem-estar, de "estar viva" ao falar português no teletandem:

Helen: Sim, que o teletandem não é aula tradicional e que não tem porque funcionar com as regras, como forma tradicional de ensino, e que para mim sempre foi mais importante a comunicaçáo que a gente aprender uma língua... Entấo, é que... é mais importante comunicar que fazer qualquer outra coisa no teletandem. 
Natália: Ah, sim, eu também acho.

Helen: Pra mim foi muito importante ter as interaçóes com tudo que passou com a minha professora Catarina.

Natália: Ah!

Helen: Porque... o teletandem foi uma motivaçáo pra seguir com o estudo da língua, muito importante, e eu tenho que dizer esto pra você... É que você me lembrou de que a língua é uma coisa viva. Não importa que Catarina diga de limpar a minha língua portuguesa. Que Catarina fique com a sua limpeza..Que fique com ela, eu estou contente com o meu português brasileiro porque é vivo e eu posso falar com você.

Natália: (ri) Que bom! Fico feliz!

H: Sim. Então, mas tudo foi muito bom (ri), então eu acho que é uma experiência muito boa. (Interação 13, em teletandem, 2007).

Ao afirmar que o teletandem foi mais importante como comunicação do que como aprendizagem de línguas, Helen parece acreditar que comunicar-se, por meio do português, foi mais relevante do que propriamente aprender aspectos formais da língua. Nas partes destacadas do trecho, a mexicana expressa uma visão muito positiva do que representou interagir no teletandem, pois, segundo ela, pôde se sentir motivada a continuar estudando e "contente com o seu português brasileiro", além de compreender e usar a língua portuguesa viva. Helen também explicita uma crítica às aulas de Catarina, que, embora fosse uma boa professora, manifestava uma ideia preconceituosa a respeito do português que Helen aprendia com Natália, a ponto de querer "varrê-lo" de Helen. A partir dessas afirmações, podemos dizer que Helen constrói em seu discurso duas metáforas bastante marcantes em seu processo de avaliação da aprendizagem de PLE: a da "limpeza da aula tradicional"e a do "português brasileiro como língua viva"(linha 13). Compreendemos, assim, aspectos relacionados ao multilinguismo e ao multiculturalismo em ambiente de aprendizagem, já que temos uma mexicana, falante bilíngue de espanhol e inglês, desenvolvendo estudos de pós-graduação na Espanha, onde tem aulas presenciais de PLE com uma portuguesa e aulas virtuais com uma brasileira. Portanto, temos um contexto carregado de ideologias que acabam por interferir na aprendizagem, tal como aconteceu entre Catarina e Helen, já que a visão fragmentada da professora entre "Português de Portugal" (língua limpa) vs. "Português do Brasil' (língua suja) influenciou o conceito de aprendizagem de PLE construído por Helen, que acabou associando o ambiente positivo de teletandem a uma aprendizagem muito mais significativa da língua. De acordo com a definição de Helen de que o português brasileiro é "língua viva", em contexto de comunicação pelo teletandem, também poderíamos supor que o português aprendido por ela em sala de aula parece-lhe uma língua estática, talvez em razão do tratamento formal atribuído à aprendizagem, naquele contexto. Além do mais, o fato de Catarina não valorizar aquilo que Helen 
já possui em termos de conhecimento linguístico, cultural e pessoal em PLE, pode revelar uma prática pedagógica de pouco empenho na humanização do ensino e na promoção do bem-estar na aprendizagem.

Em uma sessão de mediação entre Natália e eu, observamos seu percurso reflexivo a respeito de o que o teletandem representa em termos de interaçáo e de ensino de PLE, além de seu próprio papel nessas interaçóes, diante do ensino de sua língua materna como estrangeira, constituindo uma nova categoria de análise. É o que visualizamos no trecho a seguir:

Natália: É que é assim, Marta. É... Eu sou nativa em língua portuguesa, com certeza eu falo muito melhor português do que espanhol, sem dúvida. Só que a língua espanhola... hâ... além de eu ter material pra estudar, pra preparar as minhas aulas, eu não sei, parece que com a línguaportuguesa eu só paro pra pensar quando a Helen me pergunta... e esse é o problema. E daí eu tenho que resolver esse problema de imediato. E difícil porque... eu vou pra sala de aula preparada quando eu vou ensinar espanhol. Se um aluno me pergunta alguma coisa que eu não sei eu levo na outra aula... que eu não sei... mas a maioria das coisas tá dentro daquele tema da aula. Entáo são problemas que eu consigo resolver porque eu estudei pra aquilo. Pro teletandem não, eu não sei do que a gente vai falar... a minha interação com a Helen é boa nesse ponto, ela é muito natural, ela é realmente uma interaçáo cultural, social, política...É como se eu combinasse de encontrar com a Helen e começasse a conversar com ela de coisas diversas. E eu acho que a interaçáo é positiva nesse sentido, ela é natural, é como se eu encontrasse com o meu vizinho na esquina e começasse a conversar com ele. Entáo na verdade eu sinto que quando a gente ta conversando a gente pensa pouco nas línguas e mais na comunicaçáo, como se eu estivesse conversando mesmo com uma amiga de faculdade. $\mathrm{E}$ isso eu acho legal. (Mediaçáo 2, entre Marta e Natália).

Fica claro que para Natália as interações em teletandem também são constituídas de um caráter emocional marcante, muito provavelmente pelo fato de se distanciarem de um formato tradicional e previsível de aula, o que a faz pensar em como ensinar nesse contexto. Por outro lado, isso tem gerado uma visão "positiva", "legal", espontânea do ambiente virtual construída por Natália. Aliás, para ela, tal como para Helen, a comunicação parece mais importante do que o próprio ensino formal da língua, como podemos ver nas passagens destacadas.

Como última exemplificação dessa análise, apresentamos um trecho de outra mediação entre Natália e eu, no qual ela expóe o diálogo que teve com Helen sobre sua preocupação com o fato de que os problemas que a interagente mexicana vem enfrentando com a professora Catarina, em ambiente presencial, possam desmotivá-la a aprender português. Vejamos a seguir: 
Natália: Nós falamos sobre as aulas de português dela, que eu te falei, né, que eu estava preocupada

Marta: Hum-hum.

Natália: De ela querer desistir das interações, desanimar com a língua e tal. Ela disse que não, que ela gosta, que antes de tudo ela gosta da minha companhia, de falar comigo, e ela gosta da língua portuguesa. Entáo, independente do professor ela vai continuar estudando, até porque ela tem outros meios pra estudar, né? Ela não depende só de professor, ela já é professora de língua e ela sabe o que ela tem que fazer pra aprender. E ela...ela tá chateada sim, mas com a cultura da própria professora dela. Ela tá chateada, né, ela é uma pessoa mais reservada e a Helen não tava acostumada com pessoas assim...

Marta: Parece que há alguns preconceitos, também, não é?

Natália: É, é preconceito, mas ela disse que já tá começando a saber lidar com as coisas. Ela faz o que a professora manda, a professora pediu pra ela que se ela quiser falar no português do Brasil que tudo bem, mas que pra escrever tem que ser português de Portugal. Então é o que ela tá fazendo, ela disse. Por exemplo, ela disse, eu uso o gerúndio em sala quando eu vou falar, mas na hora de escrever eu tenho que usar o infinitivo.

Marta: Ah, é?

Natália: É, entáo, ela disse que brincou com a professora dela na última aula. Ela disse que o que tava faltando era sair pra tomar um copo de cerveja(risos). Ela brincou com a professora, né...

Marta: (risos) E a professora?

Natália: A professora dela disse que deu risada, mas que ela é muito formal, ela é (lendo o texto de Helen) "Ao contrário das minhas outras professoras porque, realmente, a gente se reunia a sala inteira e a professora pra tomar cerveja à noite", e ela me falou: “Eram brasileiras, né, Natália?” A gente é mesmo menos formal, né, menos SÉRIA. (Mediação 3, entre Marta e Natália).

Em termos humanizadores, o que nos chama a atenção no trecho acima é a cumplicidade estabelecida entre Natália e Helen, no sentido de que a segunda tranquiliza a primeira quanto a sua dúvida sobre o fato de Helen poder estar desestimulada a continuar aprendendo português. Podemos finalizar a discussão desta análise com as 
reflexões de Gomes de Matos (2010), para quem visões que inferiorizam culturas, julgam e generalizam hábitos a partir de uma cultura ideal, geralmente a cultura materna, "matam a interculturalidade". Em termos educacionais, ensinar línguas estrangeiras na contemporaneidade deve levar em consideração que há valores universais, como a preservação da vida, da paz e da justiça que devem perpassar os ensinamentos em torno de todas as línguas e culturas.

\section{Considerações finais}

Voltando-nos ao título deste trabalho, podemos concluir que as emoções manifestadas pela aprendiz de PLE mexicana em teletandem estáo ligadas às próprias características daquele ambiente, que pode ser tomado como muito próximo a um contexto de imersáo, no qual a qualidade das interaçóes promove um envolvimento emocional maior e as interagentes trabalham para ajudar-se mutuamente na aprendizagem da língua uma da outra. O teletandem, no contexto analisado, representa uma possibilidade real de comunicar-se com alguém, aprender sobre sua cultura, os pensamentos e os costumes de um povo, aspectos reais que geralmente não aparecem em contextos de ensino convencionais. Portanto, as oportunidades de bem-estar são potencializadas nesse ambiente. A abordagem humanizadora intercultural ou telecultural pôde proporcionar o desenvolvimento de princípios e açóes promotoras da paz comunicativa, tais como pensar em nosso próximo linguístico, cultivar uma comunicação construtiva, promover a paz comunicativa entre as pessoas e dignificar nossos diálogos do dia a dia (GOMES DE MATOS, 2014), a ponto de nos sentirmos constantemente vivos pelo fato de usar humanizadoramente uma língua. Observamos, portanto, no caso apresentado, tratar-se de um ambiente constituído não apenas de princípios que regem uma prática de ensino de línguas e de formação docente, mas de uma filosofia de vida e de bem-estar em sociedade, movida pelo discurso humanizador.

\section{"PORTUGUESE MAKES ME HAPPY": SHARING EMOTIONS IN PFL TEACHING AND LEARNING HUMANIZING PRACTICES IN A CONTEXT MEDIATED BY COMPUTER}

- ABSTRACT: What is the relationship between learning a language and feeling yourself happy? Which contexts and actions can promote more humanizing language learning? Based on the "learning language positivelly" assumption (GOMES DE MATOS, 1996, 2009, 2010, 2014), this study aims at characterizing a multilingual and multicultural virtual context (DE OLIVEIRA, 2014), which allows humanizing practices of Portuguese as foreign language (PFL) teaching and learning. In such context, a Mexican partner shows her positive emotions and feelings about learning PFL with a Brazilian partner. She also reflects about 
your earlier and not so humanizing experiences of learning PFL and about the role of language teacher in promoting well-being sensations in learning process. The results suggest that emotions must be considered if we wish to establish a belonging and identifying learning in a multilingual and multicultural context (MURPHEY; PROBER; GONZALES, 2010; BARCELOS, 2010; PELLIM, 2010; DE OLIVEIRA, 2014) and that the humanizing content of interactions supports the success of teaching and learning process and the language teacher's reflection.

- KEYWORDS: Portuguese as a foreign language. Teaching and learning. Emotions. Humanizing approach. Multilingual and multicultural context. Language teacher education.

\section{REFERÊNCIAS}

ANDRÉ, M. E. D. A. Etnografia da prática escolar. Campinas: Papirus, 2000.

BARCELOS, A. M. F. Reflexôes, crenças e emoçóes de professores e da formadora de professores. In: BARCELOS, A. M. F.; COELHO, H. S. H. (Org.). Emoçôes, reflexóes e (trans) form(açóes) de alunos, professores e formadores de professores de línguas. Campinas: Pontes, 2010. p.57-81.

BRAMMERTS, H. Aprendizagem autônoma de línguas em tandem: desenvolvimento de um conceito. In: DELILLE, K. H.; CHICHORRO, A. (Org.). Aprendizagem autônoma de línguas em Tandem. Lisboa: Colibri, 2002. p.15-25.

BURNS, A. Analysing action research data: collaborative action research for English language teachers. Cambridge: CUP, 1999.

COELHO, H. S. H. Projeto de educaçáo continuada: rede de conversaçóes para reflexão e surgimento de novas atitudes. In: BARCELOS, A. M. F.; COELHO, H. S. H. (Org.). Emoçóes, reflexóes e (trans)form(açóes) de alunos, professores e formadores de professores de línguas. Campinas: Pontes, 2010. p.83-97.

FRIEDRICH, P. Nonkilling linguistics: practical applications. Honolulu: Center for Global Nonkilling, 2012.

GOMES DE MATOS, F. Peace linguistcs for language teachers. DELTA, São Paulo, v.30, n.2, p.415-424, 2014.

Como usar uma linguagem humanizadora: orientação para professores de línguas estrangeiras. In: MOTA, K.; SHEYERL, D. (Org.). Recortes interculturais na sala de aula de línguas estrangeiras. Salvador: Ed. da UFBA, 2010. p.24-36.

. Pedagogia da positividade: comunicaçáo construtiva em português. Recife: Ed. da UFPE, 1996. 
KFOURI-KANEOYA, M. L. C. A formaçáo inicial de professoras de línguas para/em contexto mediado pelo computador (teletandem): um diálogo entre crenças, discurso e reflexão profissional. 2008. 261f. Tese (Doutorado em Estudos Linguísticos) - Universidade Estadual Paulista, Instituto de Biociências, Letras e Ciências Exatas, São José do Rio Preto, 2008.

KRAMSCH, C. Culture in foreign language teaching. Iranian Journal of Language Teaching Research, [S.1.], v.1, n.1, p.57-78, Jan. 2013.

MURPHEY, T.; PROBER, J.; GONZALES, K. Emotional belonging precedes learning. In: BARCELOS, A. M. F.; COELHO, H. S. H. (Org.). Emoçóes, reflexóes e (trans)form(açóes) de alunos, professores e formadores de professores de línguas. Campinas: Pontes, 2010. p.43-56.

DE OLIVEIRA, L. C. Language teaching in multilingual contexts. Revista Brasileira de Linguística Aplicada, Belo Horizonte, v.14, n.2, p.265-270, 2014.

PELLIM, T. Negociando identidades: quando o aluno vira professor e o professor vira aluno. In: BARCELOS, A. M. F.; COELHO, H. S. H. (Org.). Emoçóes, reflexóes e (trans)form(açóes) de alunos, professores e formadores de professores de línguas. Campinas: Pontes, 2010. p.101-123.

TELETANDEM BRASIL. Línguas estrangeiras para todos. Projeto da Faculdade de Ciências e Letras de Assis, UNESP. Disponível em: <http://www.teletandembrasil.org/home.asp >. Acesso em: 17 abr. 2015.

UNESCO. Declaraçáo universal dos direitos linguísticos. Barcelona, 1996. 